\title{
Degenerate specificity of PDZ domains from RhoA-specific nucleotide exchange factors PDZRhoGEF and LARG
}

\author{
Katarzyna Smietana ${ }^{1}$, Monika Kasztura ${ }^{1}$, Marcin Paduch $^{1}$, Urszula Derewenda ${ }^{2}$, \\ Zygmunt S. Derewenda ${ }^{2}$ and Jacek Otlewski ${ }^{1 凶}$ \\ ${ }^{1}$ Faculty of Biotechnology, Laboratory of Protein Engineering, University of Wroctaw, Wroctaw, Poland; \\ ${ }^{2}$ Department of Molecular Physiology and Biological Physics, University of Virginia, Charlottesville, USA
}

Received: 18 April, 2008; revised: 20 May, 2008; accepted: 29 May, 2008

available on-line: 07 June, 2008

\begin{abstract}
PDZ domains are ubiquitous protein-protein interaction modules which bind short, usually carboxyterminal fragments of receptors, other integral or membrane-associated proteins, and occasionally cytosolic proteins. Their role in organizing multiprotein complexes at the cellular membrane is crucial for many signaling pathways, but the rules defining their binding specificity are still poorly understood and do not readily explain the observed diversity of their known binding partners. Two homologous RhoA-specific, multidomain nucleotide exchange factors PDZRhoGEF and LARG contain PDZ domains which show a particularly broad recognition profile, as suggested by the identification of five diverse biological targets. To investigate the molecular roots of this phenomenon, we constructed a phage display library of random carboxyterminal hexapeptides. Peptide variants corresponding to the sequences identified in library selection were synthesized and their affinities for both PDZ domains were measured and compared with those of peptides derived from sequences of natural partners. Based on the analysis of the binding sequences identified for PDZRhoGEF, we propose a sequence for an 'optimal' binding partner. Our results support the hypothesis that $\mathrm{PDZ}$-peptide interactions may be best understood when one considers the sum of entropic and dynamic effects for each peptide as a whole entity, rather than preferences for specific residues at a given position.
\end{abstract}

Keywords: binding specificity, LARG, PDZ domain, PDZRhoGEF, phage display

\section{INTRODUCTION}

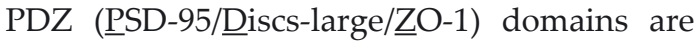
the most common protein-protein interaction modules found in the proteomes throughout the living world (Jelen et al., 2003; Ponting, 1997). They are relatively small, 80-90 amino-acid residues in length, occur in cytosolic multidomain signaling proteins, and typically interact with cognate membrane proteins, such as channels or receptors, by binding their unstructured, C-terminal 'tails'. However, non-canonical recognition of internal motifs in target proteins is also observed. Typically, the dissociation constants
$\left(K_{\mathrm{d}}\right)$ for the PDZ domains and their protein partners are in the micromolar range (Harris \& Lim, 2001). Such moderate values allow for fast reversible binding and are easily regulated by discrete changes in intracellular conditions (Nguyen et al., 1998).

Structural studies have revealed that in spite of sequence divergence, all PDZ domains share a highly conserved tertiary fold consisting of six $\beta$ strands $(\beta \mathrm{A}-\beta \mathrm{F})$ and two $\alpha$-helices $(\alpha \mathrm{A}$ and $\alpha \mathrm{B})$. The binding pocket is situated between strand $\beta \mathrm{B}$ and helix $\alpha \mathrm{B}$ and the interacting C-terminal oligopeptide from the cognate protein is inserted as an 'addition$\mathrm{al}^{\prime} \beta$-strand antiparallel to $\beta \mathrm{B}$ in a mechanism called

Corresponding author: Jacek Otlewski, Faculty of Biotechnology, Laboratory of Protein Engineering, University of Wroclaw, Tamka 2, 50-137 Wrocław, Poland; tel.: (48) 71375 2824; fax: (48) 71375 2608; e-mail: otlewski@protein.pl

Abbreviations: Dns, dansyl moiety; DTT, dithiothreitol; GdmCl, guanidinum chloride; IGF, insulin-like growth factor; IPTG, isopropyl- $\beta$-D-1-thiogalactopyranoside; LARG, leukemia-associated Rho-specific guanine nucleotide exchange factor; LPA, lysophosphatidic acid; MAP1A, microtubule-associated protein light chain; PDZ, PSD-95/Discs-large/ZO-1 homology domain; PRG, PDZRhoGEF, PDZ-containing Rho-specific guanine nucleotide exchange factor; TFA, trifluoroacetic acid; TCEP, tris(2-carboxyethyl)phosphine. 
' $\beta$-strand addition' (Harrison, 1996). The terminal carboxylate of the peptide is bound primarily by backbone amides within a Gly-rich conserved 'carboxylate binding loop' (Doyle et al., 1996), while the preceding residues are bound in an extended conformation via a combination of hydrogen bonds and hydrophobic interactions. In a canonical case, only a short stretch of four or five C-terminal amino acids of the target protein is recognized, although it has been demonstrated that in some cases even distant residues, up to the $\mathrm{P}^{-8}$ position, may have a significant impact on the binding specificities and energies (Songyang et al., 1997).

The specificities of PDZ-mediated interactions are broad and difficult to rationalize. Several attempts have been made to classify them either by their ligand preferences (Schepens et al., 1997; Songyang et al., 1997; Stricker et al., 1997; Maximov et al., 1999) or by the sequence of their binding site (Bezprozvanny \& Maximov, 2001). Most PDZ domains show preference for a hydrophobic amino acid in the C-terminal position $\left(\mathrm{P}^{0}\right)$. The so-called class I PDZ domains show high selectivity towards Ser or Thr in the $\mathrm{P}^{-2}$ position, while the class II domains favor small hydrophobic side chains in this position (Harris \& Lim, 2001). However, there are a number of PDZ domains with recognition patterns that defy such rules, including those that recognize internal motifs (Cuppen et al., 1998; Hillier et al., 1999; Wong et al., 2003; Penkert et al., 2004) or ligands with unusual residues, such as carboxyterminal cysteines, serines or charged amino acids (Maximov et al., 1999; Borrell-Pages et al., 2000; Vaccaro et al., 2001). Moreover, several PDZ domains are known to have degenerate specificity (Bezprozvanny \& Maximov, 2001; Vaccaro et al., 2001), showing comparable affinities for ligands nominally belonging to distinct classes (Vaccaro et al., 2001).

In most cases, the degenerate specificity of a particular PDZ domain becomes apparent only as a result of several independent studies, which identify different ligands, often by diverse methods. This is the case, for example, for PDZ domains found in two RhoA-specific guanine nucleotide exchange factors PDZRhoGEF (PRG) and LARG (leukemia-associated RhoGEF), members of a unique family acting downstream of heterotrimeric $\mathrm{G} \alpha_{12 / 13}$ proteins (Rossman \& Sondek, 2005). Each contains a PDZ domain in the $\mathrm{N}$-terminal portion. LARG and PRG share significant amino-acid sequence homology (overall identity $29 \%$ and similarity $62 \%$ ), especially within the fragments comprising structural and functional domains (for the PDZ domains, $74 \%$ identity and $94 \%$ similarity). This sequence similarity is reflected by a significant overlap of cellular binding partners for the two proteins (Taya et al., 2001; Swiercz et al., 2002; Yamada et al., 2005). Such close resemblance of proteins expressed in the same tissues (Hirotani et al., 2002) suggests func- tional redundancy, and/or subtle regulatory mechanisms. The elucidation of the molecular details of these mechanisms could shed some light on signaling events mediated by PRG and LARG, including cytoskeletal reorganization (Togashi et al., 2000; Swiercz et al., 2002), oncogenic transformation (Kourlas et al., 2000; Chikumi et al., 2004) and tumor-induced angiogenesis (Basile et al., 2006).

The PDZ domains from PRG (PDZ ${ }^{\mathrm{PRG}}$ ) and LARG (PDZ ${ }^{\mathrm{LARG}}$ ) were originally described as typical class I modules. Accordingly, most of their hitherto identified binding partners have a serine or a threonine in the $\mathrm{P}^{-2}$ position (insulin-like growth factor-1 (IGF-1) receptor (Taya et al., 2001), lysophosphatidic acid-1 (LPA-1) receptor (Yamada et al., 2005), CD44 (Bourguignon et al., 2006), ATPbinding cassette transporter 1 (Okuhira et al., 2005) and group B plexins (Swiercz et al., 2002)) and both domains have a histidine, located at the beginning of helix $\alpha \mathrm{B}$, which hydrogen bonds the side chain hydroxyl of the $\mathrm{P}^{-2}$ serine or threonine (Doyle et al., 1996). However, PDZ ${ }^{\mathrm{PRG}}$ also binds the microtubuleassociated protein light chain (MAP1A), a protein with a typical class II C-terminus (Longhurst et al., 2006) (Table 1). In all these binding events, except for the CD44-LARG interaction, the PDZ domain has been shown to recognize the C-terminal fragment of a partner protein, thus confirming the canonical binding mode (Taya et al., 2001; Swiercz et al., 2002; Okuhira et al., 2005; Yamada et al., 2005; Longhurst et al., 2006). The sequential diversity of the natural binding partners of both PDZ domains has led us to hypothesize that the mechanism of protein partner recognition is more complex in these proteins than originally assumed. To address this question we used combinatorial and biophysical methods.

To obtain an unbiased profile of peptide sequence preferences of the two PDZ domains we resorted to a phage display system. Phage display offers the most common methodology for combinatorial display of peptide libraries. Although PDZ domains bind relatively short peptide fragments, typically no more than six amino-acid residues, a complete screen to identify the optimal sequence would still require $6.4 \times 10^{7}$ combinations, a number that can be screened by phage display but not easily tackled by other approaches. In this paper we describe studies of the two PDZ domains from the RhoA-specific nucleotide exchange factors, based on the concept of Fuh and coworkers (Fuh et al., 2000; Fuh \& Sidhu, 2000), who designed a spacer sequence allowing efficient display of a peptide library fused C-terminally to phage coat protein. We show that the selected sequences bind in vitro to the two PDZ domains with expected affinities, and we compare the selected peptides with those derived from natural partners of both PRG and LARG. 


\section{MATERIALS AND METHODS}

Materials and reagents. Restriction endonucleases, T7 DNA ligase, molecular weight markers and M13KE vector were purchased from New England Biolabs. Maxisorp 96-well immunoplates were from Nalge NUNC International (Naperville, IL, USA). Escherichia coli XL1-Blue, E. coli BL21, and M13-VCS were from Stratagene. Horseradish peroxidase/antiM13 antibody conjugate was from Amersham Biosciences. Degenerate oligonucleotides, PCR and sequencing primers were from MWG-Biotech AG; pComb3H vector was obtained from C. F. Barbas (The Scripps Research Institute, La Jolla, CA, USA); the TEV protease expression plasmid was kindly provided by J. A. Doudna (Lucast et al., 2001).

Peptides used in binding assays were synthesized by Bio-Synthesis (USA). They were purified on a reversed-phase C-18 Vydac column (218TP510) with a linear gradient $(1 \mathrm{ml} / \mathrm{min}, 0.1 \%$ TFA - 90\% acetonitrile $/ \mathrm{H}_{2} \mathrm{O}, \mathrm{v} / \mathrm{v}$ ), converted to acetate forms and lyophilized. The peptides were dissolved in water and their concentration was estimated from either molar absorbance coefficient of dansyl group at $334 \mathrm{~nm}$ or of the aromatic residues in the sequence. Peptide identities and purity were verified by mass spectrometry. Cysteine-containing peptides were stored in the presence of $100 \mathrm{mM}$ DTT at $-80^{\circ} \mathrm{C}$.

Vector modification. The phage-displayed library of random hexapeptides was fused to the Cterminus of the M13 phage major coat protein P8, downstream of the AWEENIDSAP linker to ensure optimal C-terminal display of peptide variants on the phage surface, following the protocol of Fuh and coworkers (Fuh et al., 2000; Fuh \& Sidhu, 2000). To that end, we modified the pComb3H vector (Barbas \& Wagner, 1995) which in its original version contained: two origins of replication (ColE1 and $\mathrm{fl}$ ), $\beta$ lactamase gene $\left(A m p^{r}\right)$ and two fusion genes ompA (encoding the Fab light chain) and pelB (Fab heavy chain and minor phage $\mathrm{P}_{230-406}$ ) under the control of the lac promoter. The coding sequence for the Fab light chain was removed with subsequent bluntend ligation to obtain pComb3 $\mathrm{H}^{\mathrm{LC}-}$ vector (Kiczak et al., 2001). The major phage P8 gene, amplified from the M13KE vector, was introduced instead of Fab heavy chain and P3 using NcoI and NheI sites. A new restriction site for SpeI endonuclease was introduced into $\mathrm{pComb3} \mathrm{H}^{\mathrm{LC}-}$ vector downstream of the phage P8 gene by site-directed mutagenesis. Finally, a linker sequence encoding the AWEENIDSAP spacer followed by hexa-His tag was obtained by hybridization of two partially complementary oligonucleotides: His6spacer ${ }_{\text {for }}$ CTAGCGCTTGGGAGGAAAACATAGACTCAGCACCAGGAGGCTCGAGCGGTCATCATCATCATCATCATTAATAA and His6spacer ${ }_{\text {rev }}$ CTAGTTATTAATGATGATG-
ATGATGATGACCGCTCGAGCCTCCTGGTGCTGAGTCTATGTTTTCCTCCCAAGCG.

The linker optimized by Fuh and coworkers (Fuh et al., 2000; Fuh \& Sidhu, 2000) was extended by an additional short spacer (GGSSG), generating a XhoI cloning site and increasing the distance between P8 and library peptides. The resulting DNA cassette was introduced downstream of phage P8 gene. Modification of the phagemid was verified by direct DNA sequencing. The display efficiency of the fusion protein was confirmed by an ELISA assay and binding to the Ni-NTA resin.

Peptide library construction and selection. The final target peptide library was generated by replacing the hexa-His tag sequence with the random-sequence peptide library insert using XhoI/SpeI restriction sites. The insert was obtained by hybridization of degenerate and phosphorylated oligonucleotides: bib $_{\text {for }}$ TCGAGCGGTNSNNSNNSNNSNNSNNSTAATAA and bib CTAGTTATTASNNSNNSNNSNNSNNSNNACCGC (where $N$ stands for equimolar contribution of $A, T$, $\mathrm{G}, \mathrm{C}$ and $\mathrm{S}$ for $\mathrm{G}$ or $\mathrm{C}$ ). The resulting cassette with sticky ends (XhoI/SpeI) was inserted into the modified phagemid $\mathrm{pComb3H}$. The final construct contained IPTG-inducible $\mathrm{P}_{\text {lac }}$ promoter, PelB signal sequence, mature P8, the linker sequence AWEENIDSAPGGSSG, randomized hexapeptide, and two consecutive stop codons. The insertion and heterogeneity of displayed peptides were confirmed by sequencing of fifteen random clones. The library was constructed with degenerate codons that encode all 20 natural amino acids and the amber stop codon, and consisted of $6.4 \times 10^{7}$ variants and yielded $1 \times 10^{7}$ transformants after cloning. This complexity is sufficient to fully randomize the last four C-terminal residues responsible for the main contacts on the PDZ domain-peptide interaction interface.

The library selection was carried out by binding $2 \times 10^{11} \mathrm{cfu} / \mathrm{ml}$ phages in Tris-buffered saline (TBS; $50 \mathrm{mM}$ Tris/ $\mathrm{HCl}, 150 \mathrm{mM} \mathrm{NaCl}, \mathrm{pH}$ 7.4) containing $0.1 \%$ BSA (bovine serum albumin) to wells coated with 5-10 $\mu \mathrm{g}$ of immobilized protein (and to wells coated with 1\% BSA used as a control experiment) for $3 \mathrm{~h}$ at room temp. Before adding phages, the wells were blocked with 1\% BSA in TBS solution. Unbound phages were removed from the wells by washing with TBS with $0.05 \%$ Tween 20 . Remaining phages were eluted with $100 \mu \mathrm{l}$ of $50 \mathrm{mM}$ glycine/ $\mathrm{HCl}$ buffer, $\mathrm{pH}$ 2.2, for $10 \mathrm{~min}$. Promptly after elution, $50 \mu \mathrm{l}$ of $1 \mathrm{M}$ Tris, $\mathrm{pH} 8$ was added to avoid phage disruption at low $\mathrm{pH}$.

Several panning experiments were conducted to determine optimal experimental conditions. Best results were obtained using $1 \%$ BSA as a blocking agent and 3 -h phage binding time. Eluting bound phages with $50 \mathrm{mM}$ glycine/ $\mathrm{HCl}, \mathrm{pH} 2.2$, was much 
more effective than with $5 \mathrm{M} \mathrm{NaCl}$. Initial panning experiments on PDZ ${ }^{\mathrm{LARG}}$ were performed in a reducing environment (100 mM DTT or TCEP, tris(2carboxyethyl)phosphine) to avoid disulfide bonding between the single cysteine present on the protein surface and cysteine-containing peptide variants. The addition of a reducing agent had a significant negative influence on phage infectivity, resulting in lowered phage titers and propagation efficiency. Since under nonreducing conditions PDZ ${ }^{\mathrm{LARG}}$ forms covalent dimers (Paduch et al., 2007), we used the dimeric form of the protein and non-reducing environment for the selection experiments.

Propagation and isolation of phages. Eluted phages were amplified by infection of E. coli ER2738 cells in LB medium containing ampicillin, tetracycline and $2 \%$ glucose. After $6 \mathrm{~h}$ of growth, glucose was removed and phagemid-containing bacteria were infected with helper phage (about 100 particles per bacterium) and grown for another $6 \mathrm{~h}$ at $37^{\circ} \mathrm{C}$. Subsequently, phages were isolated by double precipitation with $20 \%$ polyethylene glycol 8000 in $15 \%$ $\mathrm{NaCl}$. Phage pellet was dissolved in TBS and used for the next round of selection.

Phage ELISA. ELISA (96-well) plates were coated overnight with $100 \mu \mathrm{l}$ PDZ domain in TBS $(50 \mu \mathrm{g} / \mathrm{ml})$. The wells were blocked for $1 \mathrm{~h}$ with $1 \%$ BSA and rinsed five times with TBS containing $0.1 \%$ Tween 20. Phages corresponding to individual bacterial colonies were grown overnight and isolated as described above. Aliquots of $100 \mu \mathrm{l}$ of $5 \times 10^{11}$ $\mathrm{cfu} / \mathrm{ml}$ phages in TBS were added to each well and incubated at room temp. for $1 \mathrm{~h}$. Next, wells were washed five times with TBS containing $0.1 \%$ Tween 20. Binding of peptide-presenting phages to the protein was detected after $1 \mathrm{~h}$ incubation with polyclonal anti-M13 phage HRP (horseradish peroxidase)conjugated antibody and visualized by adding OPD (o-phenylenediamine dihydrochloride) substrate. The reaction was stopped with $4 \mathrm{M} \mathrm{H}_{2} \mathrm{SO}_{4}$ and absorbance determined at $490 \mathrm{~nm}$. Individual clones were sequenced based on the signal strength (compared to positive control) and the specificity of the interaction. Binding of every clone in PDZ- and BSA-coated wells was assayed, and clones interacting with the control well were discarded as non-specific.

Protein expression and purification. Expression and purification of the two PDZ domains from PDZRhoGEF and LARG was carried out as described elsewhere (Paduch et al., 2007). Briefly, PDZ ${ }^{\text {PRG }}$ (residues 46-122) was cloned into pET22b vector by blunt end ligation using NdeI and XhoI restriction sites. The construct contains a non-cleavable C-terminal hexa-His tag and a C47S mutation introduced to eliminate protein aggregation. Neither modification interferes with the ability of the domain to bind target peptides. The protein was expressed in E. coli
BL21(DE3)RIL, following induction with isopropyl- $\beta$ D-1-thiogalactopyranoside (IPTG, $0.5 \mathrm{mM}$ ) at $20^{\circ} \mathrm{C}$ to increase the yield of soluble protein in the cytosolic fraction. The cells were harvested by centrifugation and lysed by sonication in a $50 \mathrm{mM}$ Tris $\mathrm{pH} 7.5$, $150 \mathrm{mM} \mathrm{NaCl}$ buffer. Lysates were cleared by centrifugation and the protein was purified on Ni-NTA agarose with standard protocol. Protein-containing elution fractions were dialysed against $50 \mathrm{mM}$ sodium acetate, $\mathrm{pH} 5$, and ion-exchange chromatography was used to remove any remaining impurities. The protein was loaded on a MonoS HR5/5 column and eluted with linear salt gradient $(0-1 \mathrm{M} \mathrm{NaCl})$ in $50 \mathrm{mM}$ sodium acetate $\mathrm{pH} 5.0$ buffer.

The PDZ ${ }^{\text {LARG }}$ construct (residues 67-147) was expressed as a MBP-His-tag fusion protein (Nallamsetty \& Waugh, 2007) also at $20^{\circ} \mathrm{C}$. Lysates were cleared by centrifugation and the protein was purified on Ni-NTA agarose with standard protocol. Protein was eluted from Ni-NTA agarose column with an imidazole step gradient. The MBP-His-tag was removed by cleavage with rTEV protease. Undigested protein and fusion partner were removed during a second passage through the Ni-NTA agarose. Protein-containing elution fractions were dialysed against $50 \mathrm{mM}$ sodium acetate, $1 \mathrm{mM}$ TCEP, $\mathrm{pH} \mathrm{5}$, and the protein was loaded on an SP-Sepharose column and eluted with a linear salt gradient (0-1 M NaCl).

The purity of both proteins was confirmed by SDS/PAGE and mass spectrometry. Protein samples were concentrated to at least $1 \mathrm{mM}$ as calculated from the molar absorbance coefficients at $280 \mathrm{~nm}$ $\left(\varepsilon_{280 \mathrm{PRG}}=6400 \mathrm{M}^{-1} \mathrm{~cm}^{-1}\right.$ and $\left.\varepsilon_{280 \mathrm{LARG}}=1400 \mathrm{M}^{-1} \mathrm{~cm}^{-1}\right)$.

Binding measurements. The binding of synthetic dansylated peptides to PDZ ${ }^{\text {PRG }}$ and PDZ ${ }^{\text {LARG }}$ was measured by monitoring changes in fluorescence of $1 \mu \mathrm{M}$ buffered peptide solution upon titration with concentrated protein. All measurements were conducted in a $1 \mathrm{~cm} \times 1 \mathrm{~cm}$ stirred cuvette containing $1.2 \mathrm{ml}$ of $20 \mathrm{mM}$ sodium phosphate, 150 $\mathrm{mM} \mathrm{NaCl}(\mathrm{pH} \mathrm{7.0)}$ and/or in $50 \mathrm{mM}$ sodium acetate ( $\mathrm{pH}$ 5.0). The protein stocks of 1 to $1.5 \mathrm{mM}$ were used and the signal change was corrected for dilution. Data were analyzed by nonlinear least-squares analysis using Grafit 3.01 (Erithacus Software) and the equation:

$\mathrm{y}=\mathrm{F}_{0}+\left(\left(\mathrm{F}_{\max }-\mathrm{F}_{0}\right) \times \mathrm{c} / \mathrm{K}_{\mathrm{d}}\right) /\left(1+\mathrm{c} / \mathrm{K}_{\mathrm{d}}\right)$

where $\mathrm{y}$ is the fluorescence signal, $c$ is the concentration of protein, $K_{d}$ is the dissociation constant, $\mathrm{F}_{0}$ is the initial fluorescence value, and $\mathrm{F}_{\max }$ is the maximal fluorescence value at saturation (Harris et al., 2001). Experiments were performed at $21^{\circ} \mathrm{C}$ using an FP-750 spectrofluorimeter (Jasco) equipped with an ETC 272T Peltier accessory at the following 
conditions: excitation wavelength $335 \mathrm{~nm}$ for Dns (295 nm in case of monitoring tryptophan fluorescence), emission wavelength $540 \mathrm{~nm}$ for Dns (361 $\mathrm{nm}$ for Trp), excitation and emission slit widths of $5 \mathrm{~nm}$. Data were collected at medium sensitivity and averaged for $500 \mathrm{~s}$ for each data point. Minimum three measurements were conducted for each PDZ-peptide combination. After the initial fit, data were normalized and a nonlinear regression analysis including an F-test comparison was performed. $K_{d}$ and standard error values calculated from the comparison of fits are shown in Tables 2 and 3.

An alternative, qualitative assay was based on equilibrium guanidinium chloride $(\mathrm{GdmCl})$ denaturation of PDZ-peptide complexes and free PDZ ${ }^{\text {PRG, }}$ performed on a J-715 spectropolarimetr (Jasco) at $21^{\circ} \mathrm{C}$ in $1.5 \mathrm{ml}$ of $20 \mathrm{mM}$ sodium phosphate buffer $\left(\mathrm{pH}\right.$ 7.0). The purified His-tagged PDZ ${ }^{\text {PRG }}$ domain $(2 \mu \mathrm{M})$, either free or saturated with bound peptide (LVYMVL $(20 \mu \mathrm{M})$ or LCSPLV $(20 \mu \mathrm{M}))$ was equilibrated in a set of increasing $\mathrm{GdmCl}$ concentrations. The secondary structure content was monitored for each of the samples by the decrease of the CD signal at $222 \mathrm{~nm}$ averaged for $60 \mathrm{~s}$ at $2 \mathrm{~nm}$ bandwidth. An increase in stability was interpreted qualitatively as evidence of binding.

\section{RESULTS}

Identification of PDZ-interacting C-terminal peptides

Five rounds of selection were conducted to identify the cognate sequences for the PDZ ${ }^{\mathrm{PRG}}$ domain, resulting in a 300-fold enrichment relative to the control experiment. A second panning experiment was carried out independently with the same library packed in the presence of IPTG, which increased the number of fusion P8 protein copies on each phage particle as a consequence of Lac induction. This resulted in a more rapid enrichment (300fold after only three selection rounds) (Fig. 1). The panning was concluded at this point, because its continuation resulted in a decrease of the enrichment ratio. One probable explanation is that the prevalence of highly hydrophobic sequences in the selected pool of binders may have caused the specific phages to aggregate and thus prevented them from efficiently infecting the $E$. coli cells. In the case of PDZ ${ }^{\text {LARG, }}$, the library was packed in the presence of IPTG and the enrichment ratios obtained in the first four selection rounds were lower, reaching the maximum of 28 -fold. The continuation of the experiment beyond the fourth round resulted in an increased enrichment ratio, but all the sequenced variants contained single cysteines, suggesting possible

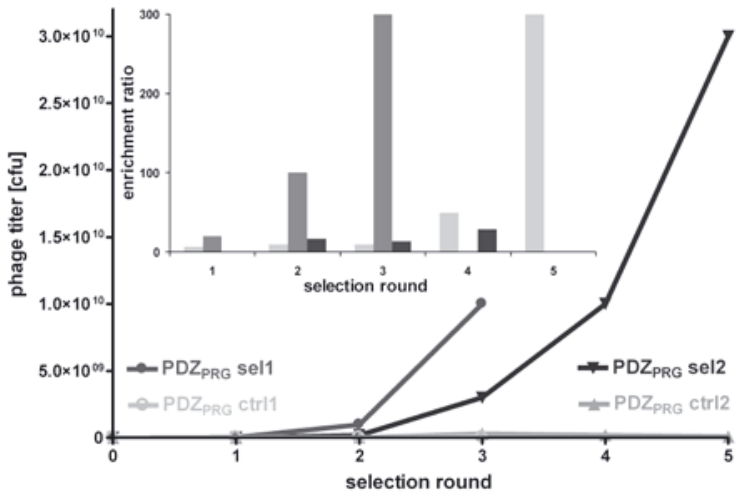

Figure 1. Phage titers during selection experiments. sel1 and ctrl1 show selection and control phage titers for the panning of the library packed in the presence of IPTG; sel2 and ctrl2 show the experiment without IPTG. Enrichment ratios for both PDZ ${ }^{\text {PRG }}$ selections (first and second bar) and a PDZ ${ }^{\text {LARG }}$ panning (third bar) are shown in the inset.

interaction with the cysteine on the protein's surface instead of binding within the PDZ pocket. Thus, the fifth-round peptides were discarded and panning was concluded at the fourth round. This consideration was applicable only to PDZ ${ }^{\mathrm{LARG}}$ selection, since PDZ ${ }^{\text {PRG }}$ does not contain any cysteine residues.

Individual phage clones were propagated and phage ELISA was conducted to confirm their binding to the respective PDZ domain. A total of 21 clones characterized by best signal-to-control ratios from PDZ ${ }^{\text {PRG }}$ selection and 13 from the fourth round of PDZ ${ }^{L A R G}$ panning were sequenced. The binding variants originating from both IPTG selections were very diverse, while clones from the first panning experiment (without IPTG) were dominated by only two variants. The sequences of these peptides (Table 1) include not only the expected class I PDZ ligands, but also class II and class III-like variants (Maximov et al., 1999). Even though no peptides identical to segments of known PRG or LARG natural binding proteins were identified among the selected variants, apparent similarities were observed in several cases (e.g., LRSSPW, VQSSQI and PQSSTC, where the first two peptides belong to the sequences selected on PDZ ${ }^{\mathrm{PRG}}$ and PDZ ${ }^{\mathrm{LARG}}$, respectively, and the third is the C-terminal portion of IGF-1 receptor, a cellular partner of both PDZ domains). The observed similarities as well as the successful binding experiments of three types (phage ELISA, fluorescence and stability measurements) confirm the reliability of the selection experiments.

\section{Binding of peptides to the PDZ domains}

A number of peptides corresponding to selected sequences, as well as peptides corresponding 
Table 1. C-terminal sequences selected in phage display experiments and natural PDZ ${ }^{\text {PRG }}$ and PDZ ${ }^{\text {LARG }}$ target peptides.

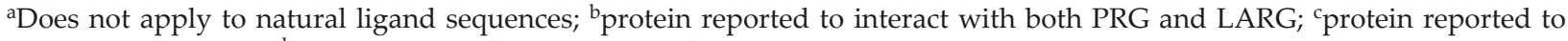
interact with LARG; ${ }^{\mathrm{d}}$ protein reported to interact with PRG.

\begin{tabular}{|c|c|c|c|c|c|c|c|c|}
\hline \multirow{2}{*}{$\begin{array}{l}\text { Source protein/selection } \\
\text { experiment }\end{array}$} & \multirow{2}{*}{$\begin{array}{l}\text { Number of } \\
\text { clones }^{\text {a }}\end{array}$} & \multirow{2}{*}{$\begin{array}{l}\text { Canonical specificity } \\
\text { class }\end{array}$} & \multicolumn{6}{|c|}{ Sequence } \\
\hline & & & $\mathrm{P}^{-5}$ & $\mathrm{P}^{-4}$ & $\mathrm{P}^{-3}$ & $\mathrm{P}^{-2}$ & $\mathrm{P}^{-1}$ & $\mathrm{P}^{0}$ \\
\hline \multirow{2}{*}{$\begin{array}{l}\text { PDZ }{ }^{\text {PRG }} \text { non-IPTG se- } \\
\text { lection }\end{array}$} & 4 & class II & $\mathrm{L}$ & $\mathrm{C}$ & $S$ & $\mathrm{P}$ & $\mathrm{L}$ & $\mathrm{V}$ \\
\hline & 3 & class II & $\mathrm{L}$ & $\mathrm{V}$ & Y & $\mathrm{M}$ & $\mathrm{V}$ & $\mathrm{L}$ \\
\hline \multirow{14}{*}{ PDZ ${ }^{\text {PRG }}$ IPTG selection } & 1 & class II & $\mathrm{F}$ & $\mathrm{A}$ & $\mathrm{P}$ & $\mathrm{F}$ & A & $\mathrm{L}$ \\
\hline & 1 & class II & $\mathrm{V}$ & Y & G & $\mathrm{W}$ & $\mathrm{L}$ & $\mathrm{V}$ \\
\hline & 1 & class II & $\mathrm{V}$ & A & $\mathrm{R}$ & $\mathrm{V}$ & Y & W \\
\hline & 1 & class II & $\mathrm{M}$ & $\mathrm{R}$ & $S$ & $\mathrm{~V}$ & $\mathrm{H}$ & $\mathrm{V}$ \\
\hline & 1 & similar to class IV & $\mathrm{L}$ & $\mathrm{W}$ & $S$ & $\mathrm{~F}$ & S & K \\
\hline & 1 & class II & $\mathrm{L}$ & $\mathrm{L}$ & $\mathrm{T}$ & $\mathrm{Y}$ & $\mathrm{R}$ & $\mathrm{P}$ \\
\hline & 1 & class I & $\mathrm{H}$ & Q & $\mathrm{E}$ & $\mathrm{S}$ & $\mathrm{R}$ & M \\
\hline & 1 & class I & $\mathrm{L}$ & $\mathrm{R}$ & $S$ & $S$ & $\mathrm{P}$ & W \\
\hline & 1 & class II & G & $\mathrm{P}$ & $\mathrm{V}$ & I & $\mathrm{L}$ & A \\
\hline & 1 & similar to class III & $\mathrm{M}$ & $\mathrm{E}$ & A & $\mathrm{R}$ & $\mathrm{L}$ & $\mathrm{D}$ \\
\hline & 1 & class III & $\mathrm{Y}$ & $\mathrm{V}$ & $\mathrm{C}$ & $\mathrm{R}$ & $\mathrm{F}$ & A \\
\hline & 1 & class III & Y & $\mathrm{A}$ & $\mathrm{L}$ & $\mathrm{R}$ & $\mathrm{R}$ & A \\
\hline & 1 & class II & $\mathrm{L}$ & S & $\mathrm{V}$ & $\mathrm{L}$ & $\mathrm{D}$ & A \\
\hline & 1 & similar to class IV & $S$ & $\mathrm{~V}$ & $\mathrm{~V}$ & $\mathrm{~L}$ & $\mathrm{P}$ & $\mathrm{R}$ \\
\hline \multirow{13}{*}{ PDZ ${ }^{\text {LARG }}$ IPTG selection } & 1 & class II & $\mathrm{L}$ & $\mathrm{F}$ & $\mathrm{F}$ & $\mathrm{M}$ & $\mathrm{R}$ & $\mathrm{L}$ \\
\hline & 1 & class I & $\mathrm{V}$ & Q & $S$ & $S$ & Q & $\mathrm{I}$ \\
\hline & 1 & class II & $\mathrm{T}$ & I & S & $\mathrm{L}$ & A & $\mathrm{L}$ \\
\hline & 1 & similar to class II & $\mathrm{R}$ & $\mathrm{F}$ & G & $\mathrm{L}$ & $\mathrm{R}$ & S \\
\hline & 1 & similar to class III & G & $\mathrm{F}$ & $\mathrm{T}$ & $\mathrm{H}$ & Q & $S$ \\
\hline & 1 & similar to class III & $\mathrm{N}$ & G & $\mathrm{C}$ & K & $S$ & $\mathrm{~T}$ \\
\hline & 1 & similar to class I & G & $\mathrm{A}$ & $S$ & $\mathrm{~T}$ & $\mathrm{~V}$ & $S$ \\
\hline & 1 & class II & $\mathrm{Y}$ & $\mathrm{Y}$ & $S$ & $\mathrm{~W}$ & $S$ & $\mathrm{~V}$ \\
\hline & 1 & class II & $\mathrm{Y}$ & G & G & G & $S$ & $\mathrm{~F}$ \\
\hline & 1 & class I & G & S & G & $S$ & $\mathrm{H}$ & $\mathrm{F}$ \\
\hline & 1 & class IV & $\mathrm{A}$ & $\mathrm{P}$ & $\mathrm{P}$ & $\mathrm{Q}$ & $\mathrm{Y}$ & $\mathrm{H}$ \\
\hline & 1 & class I & $\mathrm{M}$ & $\mathrm{D}$ & $\mathrm{P}$ & $\mathrm{T}$ & $\mathrm{R}$ & $\mathrm{P}$ \\
\hline & 1 & similar to class I & $\mathrm{C}$ & $\mathrm{P}$ & $\mathrm{R}$ & $\mathrm{S}$ & $\mathrm{L}$ & Q \\
\hline \multicolumn{2}{|l|}{ plexin $B 1^{b}$} & class I & $\mathrm{N}$ & $\mathrm{K}$ & $\mathrm{V}$ & $\mathrm{T}$ & $\mathrm{D}$ & $\mathrm{L}$ \\
\hline \multicolumn{2}{|l|}{$\mathrm{CD}_{4} 4^{\mathrm{c}}$} & similar to class I & $\mathrm{V}$ & $\mathrm{N}$ & $\mathrm{R}$ & $\mathrm{S}$ & $\mathrm{L}$ & $\mathrm{S}$ \\
\hline \multicolumn{2}{|l|}{ LPA-1 receptor ${ }^{b}$} & class II & $\mathrm{N}$ & $\mathrm{D}$ & $\mathrm{H}$ & $\mathrm{S}$ & $\mathrm{V}$ & $\mathrm{V}$ \\
\hline \multicolumn{2}{|l|}{ IGF-1 receptor ${ }^{b}$} & similar to class I & $\mathrm{P}$ & Q & $\mathrm{S}$ & $\mathrm{S}$ & $\mathrm{T}$ & $\mathrm{C}$ \\
\hline \multicolumn{2}{|c|}{ ATP-binding cassette transporter $1^{\mathrm{b}}$} & class I & $\mathrm{V}$ & $\mathrm{K}$ & $\mathrm{E}$ & $\mathrm{S}$ & $\mathrm{Y}$ & $\mathrm{V}$ \\
\hline \multicolumn{2}{|c|}{ microtubule-associated protein $^{\mathrm{d}}$} & class II & $\mathrm{A}$ & $\mathrm{C}$ & $\mathrm{K}$ & $\mathrm{I}$ & $\mathrm{E}$ & $\mathrm{F}$ \\
\hline
\end{tabular}

to previously reported natural targets of both PDZ domains, were synthesized and assayed for binding (Fig. 2, Table 2). The phage display-selected peptides for PDZ ${ }^{\mathrm{PRG}}$ included two peptides (LCSPLV and LVYMVL) dominating the pool of phages in the non-IPTG selection on PDZ ${ }^{\mathrm{PRG}}$, as well as four additional peptides representing three different classes of PDZ ligands (LRSSPW for class I, LSVLDA and VARVYW for class II, and YVCRFA for class III). The two synthesized PDZ ${ }^{\text {LARG }}$ target peptides represented class I (VQSSQI) and class II (LFFMRL). Finally, we obtained synthetic peptides corresponding to the C-terminal octapeptide sequences of the following targets of PDZ ${ }^{\text {PRG }}$ and PDZ ${ }^{\text {LARG: }}$ lysophosphatidic acid receptor (both $\mathrm{PDZ}^{\mathrm{PRG}}$ and $\mathrm{PDZ}{ }^{\mathrm{LARG}}$ ), microtubule associated protein $1 \mathrm{~A}\left(\mathrm{PDZ} \mathrm{PRG}^{\mathrm{PRG}}\right.$, plexin (both PDZ ${ }^{\text {PRG }}$ and PDZ ${ }^{\mathrm{LARG}}$ ), CD44 (PDZ ${ }^{\mathrm{LARG}}$ ) and insulin-like growth factor receptor (PDZ ${ }^{\mathrm{LARG}}$ ).

Due to the high predicted hydrophobicity of all these peptides (except for VQSSQI), a polar tetrapeptide EESG was added at the N-termini of all phage display-selected hexapeptides, and an EE dipeptide was added at the N-termini of all octapeptides corresponding to natural targets. The peptides were dansylated at the free $\alpha$-amino group. To address the possible impact of the N-terminal glutamate residues and/or the dansyl moiety, one of the peptides was synthesized in two variants - DnsSGVARVYW and EESGVARVYW. Measurements for both were conducted by monitoring changes in fluorescence signal of the N-terminal dansyl (where applicable) and the C-terminal tryptophan upon 


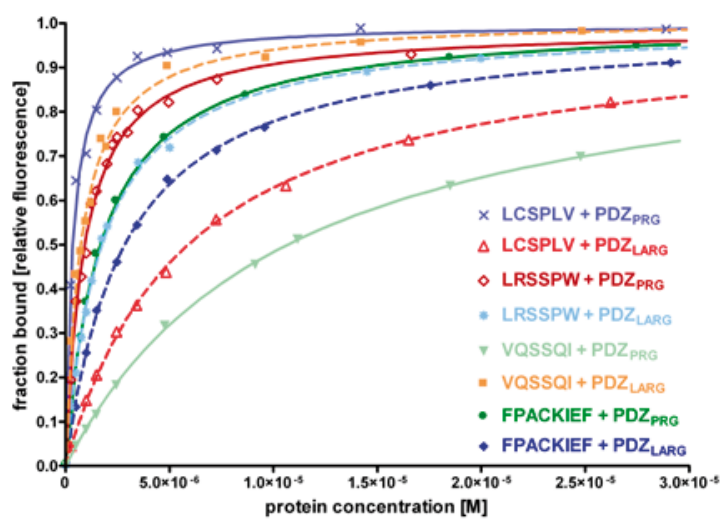

Figure 2. Binding curves for the interactions between representative peptide variants and the PDZ domains. Fluorescence data were normalized and presented as the fraction of bound peptide versus protein concentration.

binding to $\mathrm{PDZ}{ }^{\mathrm{PRG}}$. The data indicate that neither the diglutamate nor the dansyl moiety influence the peptide binding by PDZ ${ }^{\mathrm{PRG}}$. It also confirmed equal applicability of N-terminal dansyl and C-terminal tryptophan fluorescence signals in measurements of PDZ-peptide interactions.

Initial measurements were conducted in 50 $\mathrm{mM}$ sodium phosphate, $150 \mathrm{mM} \mathrm{NaCl}, \mathrm{pH} 7$, to ensure conditions similar to physiological. However, in many instances precipitation of the protein-peptide complex was observed, preventing accurate determination of the dissociation constants. The precipitation was significantly reduced at lower $\mathrm{pH}$, and thus 50 $\mathrm{mM}$ sodium acetate, $\mathrm{pH} \mathrm{5}$, was used for most measurements. Control experiments performed on three different peptides showed no significant influence of the buffer conditions on the dissociation constants.

Table 2. Dissociation constants for $P D Z^{P^{P G}}-$ and $P D Z^{L_{A R G}}$-peptide complexes.

anteraction measured by monitoring the fluorescence of C-terminal tryptophan; ${ }^{b}$ measured qualitatively using CD-based stability assay.

\begin{tabular}{llll}
\hline \multirow{2}{*}{ Peptide } & \multirow{2}{*}{ Source } & \multicolumn{2}{c}{$K_{\mathrm{d}}[\mu \mathrm{M}]$} \\
\cline { 3 - 4 } & & PDZ $^{\text {PRG }}$ & PDZ $^{\text {LARG }}$ \\
\hline Dns-EESGLCSPLV & PDZ $^{\text {PRG }}$ selection & $0.38( \pm 0.03)$ & $5.91( \pm 0.20)$ \\
Dns-EESGYVCRFA & PDZ $^{\text {PRG }}$ selection & $2.33( \pm 0.09)$ & no interaction \\
EESGLRSSPW & PDZ $^{\text {PRG }}$ selection & $0.90( \pm 0.06)^{\mathrm{a}}$ & $1.75( \pm 0.12)^{\mathrm{a}}$ \\
Dns-EESGLSVLDA & PDZ $^{\text {PRG selection }}$ & $1.33( \pm 0.10)$ & $8.15( \pm 0.91)$ \\
Dns-SGVARVYW & PDZ $^{\text {PRG selection }}$ & $8.77( \pm 0.69)$ & $3.24( \pm 0.40)$ \\
& & $8.79( \pm 0.73)^{\mathrm{a}}$ & \\
EESGVARVYW & & $8.95( \pm 1.34)^{\mathrm{a}}$ & \\
Dns-KKLVYMVL & PDZ $^{\text {PRG selection }}$ & $+\mathrm{b}$ & not measured \\
Dns-SGVQSSQI & PDZ $^{\text {LARG selection }}$ & $10.67( \pm 0.28)$ & $0.75( \pm 0.05)$ \\
Dns-EESGLFFMRL & PDZ $^{\text {LARG selection }}$ & no interaction & no interaction \\
Dns-EEFPACKIEF & MAP1A & $1.71( \pm 0.06)$ & $2.85( \pm 0.13)$ \\
Dns-EEPLPQSSTC & IGF-1 receptor & $2.08( \pm 0.20)$ & $3.95( \pm 0.18)$ \\
Dns-EEHSNDHSVV & LPA-1 receptor & $3.74( \pm 0.30)$ & $0.52( \pm 0.06)$ \\
Dns-EESNVNRSLS & CD44 & no interaction & $5.83( \pm 0.49)$ \\
Dns-EEVENKVTDL & Plexin B1 & $36.03( \pm 3.72)$ & $13.00( \pm 0.70)$ \\
\hline
\end{tabular}

The binding constants for most peptides were determined using fluorescence saturation experiments (the LVYMVL peptide was not sufficiently soluble, but its interaction with the PDZ domains was ascertained qualitatively by a stability assay, as described in Methods). One of the phage display peptides (LFFMRL, selected on PDZ ${ }^{\mathrm{LARG}}$ ) surprisingly failed to interact with either PDZ domain, and one (YVCRFA) was bound only by PDZ ${ }^{\text {PRG }}$ (the domain it was selected on). The lack of interaction in the case of the LFFMRL peptide can be attributed to the multivalent display format which occasionally leads to the selection of very weak binders if they are present on the phage surface in a large number of copies. Other synthetic ligands derived from phage display interacted with both PDZ modules, confirming the overall similarity of their recognition mechanisms. In general, the peptides were bound more strongly by the domain they were selected on, illustrating how the phage display method allows the detection of discrete variations in the protein recognition pattern. The measured $K_{d}$ values have a fairly narrow range, from 0.3 to $10.7 \mu \mathrm{M}$, and are within the range of previously characterized interactions between PDZ domains and their ligands (Laura et al., 2002; Jelen et al., 2003; Zhang et al., 2006).

As expected, all peptides based on the natural partners of either PDZ ${ }^{\text {PRG }}$ or PDZ ${ }^{\mathrm{LARG}}$ bound to their cognate domains, thus providing independent confirmation of the biological relevance of these interactions. Furthermore, since in each case we tested both PDZ domains, we discovered that the MAP1A sequence also binds to LARG (it was reported to interact with PRG, but no data were available for LARG), and the insulin-like growth factor receptor sequence, previously implicated only in an interaction with LARG, exhibited affinity also for PRG. These peptides bound to PDZ ${ }^{\text {PRG }}$ and PDZ ${ }^{\text {LARG }}$ with $K_{d}$ values from 0.8 to $36.0 \mu \mathrm{M}$, i.e. within the same range as those selected by phage display.

\section{Design and alanine-scanning analysis of the optimal PDZ ${ }^{\text {PRG }}$ peptide ligand}

A specificity profile was built for PDZ ${ }^{\text {PRG }}$ based on the amino acid frequencies observed in the phage display peptides and the substitution costs calculated using BLOSUM45 matrix (Henikoff \& Henikoff, 1992). The peptide composed of the most favored (highest scoring) residues in each 


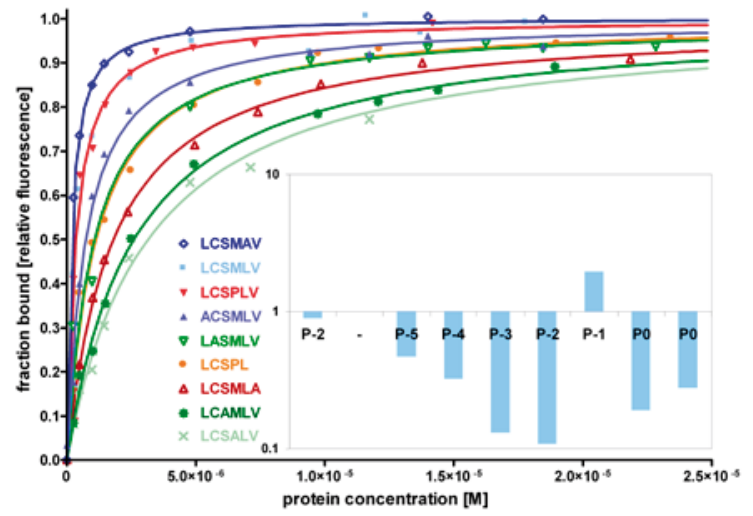

Figure 3. Binding curves for the interactions between variants of predicted optimal $P Z^{P R G}$ ligand and PDZ ${ }^{\text {PRG }}$.

Fluorescence data were normalized and presented as the fraction of bound peptide versus protein concentration. The effect of amino acid substitutions at various ligand positions is shown in the inset.

position was predicted to be an optimal target for PDZ ${ }^{\text {PRG }}$. A synthetic peptide corresponding to this sequence (LCSMLV), and extended at the N-terminus by the Dns-EESG fragment, was synthesized. Its affinity for PDZ ${ }^{\text {PRG }}$ was slightly higher than that of the strongest binder from phage display selection, peptide LCSPLV $\left(K_{\mathrm{d}}=0.34 \mu \mathrm{M}\right.$ and $0.38 \mu \mathrm{M}$, respectively) (Table 3).

To address the question of the importance of amino acids in specific positions in the peptide sequence, a set of single alanine-substituted variants of the optimal ligand were synthesized. All substitutions but one (LCSMAV) had a negative effect on the binding, with a maximum of interaction $\Delta G$ increase of over $5400 \mathrm{~J} / \mathrm{mol}$ observed for the substitution in $\mathrm{P}^{-2}$ position (Fig. 3 and Table 3). This relatively low impact of the single amino acid substitutions suggests that binding may not be additive and that cooperative effects can be more important than the interactions of any of the specific residues with

Table 3. Dissociation constants for PDZ ${ }^{\text {PRG }}$ complexes with predicted optimal peptide ligand and its variants

\begin{tabular}{llll}
\hline Peptide & Substitution position & $K_{\mathrm{d}}[\mu \mathrm{M}]$ & $\begin{array}{l}\Delta \Delta G\left(\Delta G_{\mathrm{opt}}-\Delta G\right) \\
{[\mathrm{J} / \mathrm{mol}]}\end{array}$ \\
\hline Dns-EESGLCSMLV & $\begin{array}{l}\text { none (optimal ligand) } \\
\text { P-2 (best interacting } \\
\text { peptide from C-terminal } \\
\text { phage display) }\end{array}$ & $0.34( \pm 0.02)$ & 0 \\
Dns-EESGLCSPLV & $0.38( \pm 0.03)$ & -11 \\
Dns-EESGACSMLV & P-5 & $0.73( \pm 0.07)$ & 1854 \\
Dns-EESGLASMLV & P-4 & $1.05( \pm 0.23)$ & 2768 \\
Dns-EESGLCAMLV & P-3 & $2.60( \pm 0.15)$ & 4974 \\
Dns-EESGLCSALV & P-2 & $3.14( \pm 0.26)$ & 5439 \\
Dns-EESGLCSMAV & P-1 & $0.18( \pm 0.01)$ & -1629 \\
Dns-EESGLCSMLA & P0 & $1.78( \pm 0.07)$ & 4055 \\
\hline
\end{tabular}

the binding pocket. This explanation is also consistent with the observed degenerate binding profile of both PDZ domains. The fact that the sequence of the strongest-binding peptide (LCSMAV) was not represented by any of the phage-selected variants may have resulted from the multivalent display format, a not fully representative library or, perhaps, the limited number of sequenced clones.

\section{DISCUSSION}

Phage display is a powerful technique for investigating the binding specificities in protein-ligand interactions (Clackson \& Wells, 1994). In a classical approach, ligand libraries are displayed as fusions to the N-terminal part of one of the phage coat proteins (Smith \& Scott, 1993). Due to technical problems stemming from difficulties associated with displaying C-terminal sequences on the phage surface, there are only a few studies utilizing this method for PDZ domain analysis (Vaccaro et al., 2001; Laura et al., 2002; van den Berk et al., 2005; Zhang et al., 2006; Berk et al., 2007; Runyon et al., 2007; Tonikian et al., 2007; Zhang et al., 2007). This severely limits our understanding of the structural biology of PDZ domains, because their specificity is often judged based on individual interactions, which may neither be the most physiologically relevant ones nor show particularly high affinity.

In the first reported application of C-terminal phage display (Jespers et al., 1995), the peptide display efficiency was about 100-fold lower than in the amino-terminal phage display and did not allow for an efficient and reliable selection. The difficulties in C-terminal display of peptides were overcome by the use of an optimized 10-residue linker sequence, AWEENIDSAP, selected specifically to increase display of C-terminally attached hexa-His tag (Fuh et al., 2000; Fuh \& Sidhu, 2000). The display levels achieved with this method were comparable to those obtained in the amino-terminal phagemid systems. This library was successfully panned against several PDZ domains and yielded peptide variants interacting with PDZ domains from erbin (Laura et al., 2002) and more recently Densin180, Scribble, ZO-1 (Zhang et al., 2006), HtrA1, HtrA3 (Runyon et al., 2007) and HtrA2 (Zhang et al., 2007). In another successful application of C-terminal phage display to PDZ domain specificity studies $\lambda$ phage 
was employed instead of the filamentous M13 (Vaccaro et al., 2001; van den Berk et al., 2005; Berk et al., 2007). The work presented in this paper follows the strategy used by the Genentech group with the M13 system, with minor modifications of the cloning details giving the linker extended by five residues.

Our selection results confirmed the expected complex preference profiles for the target sequenc-

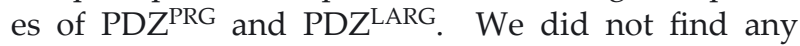
strong selection for any specific amino acid at any position in the screened hexapeptide sequences. Of particular interest are the $\mathrm{P}^{0}$ and $\mathrm{P}^{-2}$ positions which define the ligand class according to the canonical model. For the most ubiquitous class I and class II interactions, the $\mathrm{P}^{0}$ position is occupied in both cases by a hydrophobic residue, but the $\mathrm{P}^{-2}$ position is taken up either by $\mathrm{S} / \mathrm{T}$ in the former case and by a hydrophobic residue in the latter. Class III peptides contain a charged residue in the $\mathrm{P}^{-2}$ position. Our data are consistent with both PDZ ${ }^{\text {PRG }}$ and PDZLARG exhibiting the expected preference for hydrophobic amino acids at the $\mathrm{P}^{0}$ position, in agreement with the canonical mode of binding, although several variants from PDZ ${ }^{\text {LARG }}$ selection notably have noncanonical $\mathrm{S} / \mathrm{T}$ residues.

Given that four out of five physiologically relevant ligands for PDZ ${ }^{\text {PRG }}$ and PDZ ${ }^{\text {LARG }}$ contain Ser/ Thr in the $\mathrm{P}^{-2}$ position (see Table 1), we expected to find more clones corresponding to class I PDZ sequences. Surprisingly, only two of the $\mathrm{PDZ}^{\mathrm{PRG}}$ - and four of the PDZLARG-selected peptide variants represent this class. Three of the selected sequences contain Arg at $\mathrm{P}^{-2}$, suggesting specific recognition of class III peptides. Two sequences (MEARLD and APPQYH) are similar to the atypical recognition pattern described for hINADL PDZ3 domain, designated as class IV (Vaccaro et al., 2001). Most of the remaining sequences belong to or strongly resemble class II ligands.

While the most common classification of PDZ domains does not invoke a key role for the $\mathrm{P}^{-1}$ residue, other models strongly suggest that this amino acid plays a key role in the recognition patterns, at least for some PDZ domains (Kang et al., 2003). This is consistent with a number of recent experimental studies utilizing combinatorial phage display screens. The PDZ1 domain of PTB-BL shows an exclusive preference for Trp in the $\mathrm{P}^{-1}$ position (van den Berk et al., 2005; Berk et al., 2007). A similar pattern was observed for the Htr3 PDZ domain (Runyon et al., 2007) and for Htr2/OMI PDZ (Zhang et al., 2007). The importance of the Trp residue in the $\mathrm{P}^{-1}$ position was underscored by the fact that a mutation of Trp to Ala resulted in an increase in $\mathrm{IC}_{50}$ (half maximal inhibitory concentration) of a synthetic peptide binding to Htr3 PDZ from $0.6 \mu \mathrm{M}$ to $270 \mu \mathrm{M}$ (Runyon et al., 2007). In a similar fashion, the $\mathrm{P}^{-3}$ posi- tion may play a role. The Htr3 PDZ shows a distinct preference for $G / S$ in this position, similar to PDZ1 from PTB-BL. In contrast, Htr2 is strongly biased towards aromatic residues, e.g. F/Y. Our data show a mixed preference profile. Half of the PDZ ${ }^{\text {PRG }}$ clones have hydrophobic residues in $\mathrm{P}^{-1}$, but there are also several charged amino acids. The clones selected for PDZ ${ }^{\text {LARG }}$ are highly variable in this position, with nine different amino acids represented in thirteen clones. Similarly, the $\mathrm{P}^{-3}$ position shows some preference for small residues $(A / S / T / G / C)$ in seven of the sixteen clones selected for PDZ ${ }^{\mathrm{PRG}}$, and there are four clones showing aliphatic hydrophobic residues in that position. Clones selected for PDZ ${ }^{\text {LARG }}$ show a more defined preference for small residues in $\mathrm{P}^{-3}$, with eight out of thirteen clones showing either S, G or $\mathrm{T}$. It is interesting that in the PDZ ${ }^{\mathrm{PRG}}$ experiments a strong bias towards hydrophobic residues is seen at position $\mathrm{P}^{-5}$, with leucine present in over $50 \%$ of the selected variants, suggesting that the $\mathrm{P}^{-5}$ position is in this case more important than in most PDZpeptide interactions and that the $\mathrm{P}^{-5}$ leucine may be involved in specific recognition of the relevant PDZ domain.

Interestingly, none of the selected sequences correspond directly to any of the known physiological ligands, but nearly all bind as well as the latter in the in vitro binding assays, with $K_{\mathrm{d}}$ values in the micromolar range.

It is now well established that PDZ domains vary dramatically with respect to their selectivity for cognate C-terminal peptides. For example, in a recent study employing the $\lambda$ phage display system, two of the five PDZ domains of the protein phosphatase PTP-BL, i.e. PDZ2 and PDZ4, were demonstrated to bind to diverse sequences representing all of the previously defined 'classes' of PDZ ligands (van den Berk et al., 2005). By contrast, and using the same methodology, the authors show that the PDZ1 domain shows a stringent selectivity, with the vast majority of the selected clones containing the $(\mathrm{S} / \mathrm{T}) \mathrm{WV}$ C-terminal fingerprint. In another recent example, C-terminal M13 phage display experiments performed on the PDZ domains from the HtrA protein family (Runyon et al., 2007; Zhang et al., 2007) also resulted in identification of degenerate binding patterns, with a notably high variability at the $\mathrm{P}^{-2}$ ligand position. Broad specificity was previously observed for several PDZ domains, directly and indirectly through identification of physiological ligands, including erbin (Jaulin-Bastard et al., 2001; 2002; Laura et al., 2002), syntenin PDZ2 (Kang et al., 2003) and INADL PDZ1 and PDZ6 (Vaccaro et al., 2001). This strongly suggests that the roots of the degenerate specificity may arise from interactions at positions other than the canonical $\mathrm{P}^{0}$ and $\mathrm{P}^{-2}$. There are several well described examples that emphasize 
the importance of the $\mathrm{P}^{-1}$ position: valine or tyrosine in the case of syntenin (Kang et al., 2003), tyrosine and tryptophan in the case of ZO-1 (Appleton et al., 2006), or an intramolecular disulfide bridge in the InaD-NorpA complex (Kimple et al., 2001). There is also evidence that PDZ domains may adapt through an induced fit mechanism to various sequence motifs that may appear unrelated (Basdevant et al., 2006; Gianni et al., 2006; Grembecka et al., 2006). In such cases, the non-canonical interactions might provide important regulatory mechanisms, as is the case of Tyr phosporylation at position $\mathrm{P}^{-7}$ in the erbin PDZErbB2 peptide complex (Birrane et al., 2003).

The highest affinity $\mathrm{PDZ}^{\mathrm{PRG}}$-binding peptide (LCSPLV) is almost identical to the best scoring peptide in our selection-based matrix (LCSMLV). Fluorescence experiments demonstrate that this peptide indeed binds PDZ ${ }^{\text {PRG }}$ with the highest affinity. This peptide cannot be easily assigned to any of the canonical PDZ ligand classes; however, the presence of proline in $\mathrm{P}^{-2}$ could easily be adopted by the PDZ domain and should not hinder the binding. The peptide's interaction with PDZ ${ }^{\text {LARG }}$ is significantly weaker, underscoring the accuracy of the profiling approach in discriminating between similar PDZ domains. In general, class I binders interacted more strongly with PDZ ${ }^{\mathrm{LARG}}$, while PDZ ${ }^{\text {PRG }}$ could more easily accommodate ligands belonging to class II and III (the latter showing no interaction at all with PDZ ${ }^{\mathrm{LARG}}$ ). This suggests a broader specificity range for $P Z^{\text {PRG }}$ and a recognition pattern of PDZ ${ }^{\text {LARG }}$ closer to typical class I. The relatively weak binding by PDZ domains may be connected with the possibility of regulation by discrete changes in the intracellular conditions, as well as the multitude of cellular partners the domain has to adapt to. The binding of suboptimal cellular targets suggests that the role of both investigated domains may be based more on promiscuity and allowing the binding of many varied targets than on adapting to only one partner protein. No clear preference towards a specific class of binders can be seen, which corresponds well with the varied scope of PDZ ${ }^{\text {PRG }}$ and PDZ ${ }^{\text {LARG }}$ natural binders and the low $\left(K_{d}\right.$ in the range of 20-30 $\left.\mu \mathrm{M}\right)$ affinity for their natural class I ligand, plexin B Cterminal fragment (Paduch et al., 2007).

The promiscuity and lack of clearly defined consensus residues observed in our experiments are in agreement with recent computational results (Basdevant et al., 2006), where the authors show that in the PDZ domain-peptide interactions both dynamic and entropic responses are complex-specific. The existence of broad-specificity PDZ domains, like those from PDZRhoGEF and LARG, further supports this thesis and underscores the need to reevaluate the PDZ specificity paradigm. Also, the promiscuity observed for some PDZ domains needs to be further investigated as a possible means of regulating the intricate network of intracellular interactions.

\section{Acknowledgements}

This work was supported by the Ministry of Science and Higher Education (Poland) Grant 2P04A05626 (J.O.), and NIH Grant P01HL48807 (Z.S.D.). A NATO Collaborative link grant to Z.S.D. and J.O. is gratefully acknowledged.

\section{REFERENCES}

Appleton BA, Zhang Y, Wu P, Yin JP, Hunziker W, Skelton NJ, Sidhu SS, Wiesmann C (2006) Comparative structural analysis of the Erbin PDZ domain and the first PDZ domain of ZO-1: Insights into determinants of PDZ domain specificity. J Biol Chem 281: 2231-22320.

Barbas III CF, Wagner J (1995) Synthetic human antibodies: Selecting and evolving functional proteins. Methods: A Companion to Methods in Enzymology 8: 94-103.

Basdevant N, Weinstein H, Ceruso M (2006) Thermodynamic basis for promiscuity and selectivity in proteinprotein interactions: PDZ domains, a case study. J Am Chem Soc 128: 12766-12777.

Basile JR, Castilho RM, Williams VP, Gutkind JS (2006) Semaphorin $4 \mathrm{~d}$ provides a link between axon guidance processes and tumor-induced angiogenesis. Proc Natl Acad Sci USA 103: 9017-9022.

Berk LC, Landi E, Walma T, Vuister GW, Dente L, Hendriks WJ (2007) An allosteric intramolecular PDZ-PDZ interaction modulates PTP-BL PDZ2 binding specificity. Biochemistry 46: 13629-13637.

Bezprozvanny I, Maximov A (2001) Classification of PDZ domains. FEBS Lett 509: 457-462.

Birrane G, Chung J, Ladias JA (2003) Novel mode of ligand recognition by the ERBIN PDZ domain. J Biol Chem 278: 1399-1402.

Borrell-Pages M, Fernandez-Larrea J, Borroto A, Rojo F, Baselga J, Arribas J (2000) The carboxy-terminal cysteine of the tetraspanin L6 antigen is required for its interaction with SITAC, a novel PDZ protein. Mol Biol Cell 11: 4217-4225.

Bourguignon LY, Gilad E, Brightman A, Diedrich F, Singleton P (2006) Hyaluronan-CD44 interaction with leukemia-associated RhoGEF and epidermal growth factor receptor promotes Rho/Ras co-activation, phospholipase $\mathrm{C} \varepsilon-\mathrm{Ca}^{2+}$ signaling, and cytoskeleton modification in head and neck squamous cell carcinoma cells. J Biol Chem 281: 14026-14040.

Chikumi H, Barac A, Behbahani B, Gao Y, Teramoto H, Zheng Y, Gutkind JS (2004) Homo- and hetero-oligomerization of PDZ-RhoGEF, LARG and p115RhoGEF by their C-terminal region regulates their in vivo Rho GEF activity and transforming potential. Oncogene 23: 233-240.

Clackson T, Wells JA (1994) In vitro selection from protein and peptide libraries. Trends Biotechnol 12: 173-184.

Cuppen E, Gerrits H, Pepers B, Wieringa B, Hendriks W (1998) PDZ motifs in PTP-BL and RIL bind to internal protein segments in the LIM domain protein RIL. Mol Biol Cell 9: 671-683.

Doyle DA, Lee A, Lewis J, Kim E, Sheng M, MacKinnon R (1996) Crystal structures of a complexed and peptide- 
free membrane protein-binding domain: Molecular basis of peptide recognition by PDZ. Cell 85: 1067-1076.

Fuh G, Sidhu SS (2000) Efficient phage display of polypeptides fused to the carboxy-terminus of the M13 gene-3 minor coat protein. FEBS Lett 480: 231-234.

Fuh G, Pisabarro MT, Li Y, Quan C, Lasky LA, Sidhu SS (2000) Analysis of PDZ domain-ligand interactions using carboxyl-terminal phage display. J Biol Chem 275: 21486-21491.

Gianni S, Walma T, Arcovito A, Calosci N, Bellelli A, Engstrom A, Travaglini-Allocatelli C, Brunori M, Jemth P, Vuister GW (2006) Demonstration of long-range interactions in a PDZ domain by NMR, kinetics, and protein engineering. Structure 14: 1801-1809.

Grembecka J, Cierpicki T, Devedjiev Y, Derewenda U, Kang BS, Bushweller JH, Derewenda ZS (2006) The binding of the PDZ tandem of syntenin to target proteins. Biochemistry 45: 3674-3683.

Harris BZ, Lim WA (2001) Mechanism and role of PDZ domains in signaling complex assembly. J Cell Sci 114: 3219-3231.

Harris BZ, Hillier BJ, Lim WA (2001) Energetic determinants of internal motif recognition by PDZ domains. Biochemistry 40: 5921-5930.

Harrison SC (1996) Peptide-surface association: The case of PDZ and PTB domains. Cell 86: 341-343.

Henikoff S, Henikoff JG (1992) Amino acid substitution matrices from protein blocks. Proc Natl Acad Sci USA 89: 10915-10919.

Hillier BJ, Christopherson KS, Prehoda KE, Bredt DS, Lim WA (1999) Unexpected modes of PDZ domain scaffolding revealed by structure of nNOS-syntrophin complex. Science 284: 812-815.

Hirotani M, Ohoka Y, Yamamoto T, Nirasawa H, Furuyama T, Kogo M, Matsuya T, Inagaki S (2002) Interaction of plexin-B1 with PDZ domain-containing Rho guanine nucleotide exchange factors. Biochem Biophys Res Commun 297: 32-37.

Jaulin-Bastard F, Saito H, Le Bivic A, Ollendorff V, Marchetto S, Birnbaum D, Borg JP (2001) The ERBB2/HER2 receptor differentially interacts with ERBIN and PICK1 PSD-95/DLG/ZO-1 domain proteins. J Biol Chem 276: 15256-15263.

Jaulin-Bastard F, Arsanto JP, Le Bivic A, Navarro C, Vely F, Saito H, Marchetto S, Hatzfeld M, Santoni MJ, Birnbaum D, Borg JP (2002) Interaction between Erbin and a Catenin-related protein in epithelial cells. J Biol Chem 277: 2869-2875.

Jelen F, Oleksy A, Smietana K, Otlewski J (2003) PDZ domains - common players in the cell signaling. Acta Biochim Polon 50: 985-1017.

Jespers LS, Messens JH, De Keyser A, Eeckhout D, Van den Brande I, Gansemans YG, Lauwereys MJ, Vlasuk GP, Stanssens PE (1995) Surface expression and ligandbased selection of cDNAs fused to filamentous phage gene VI. Biotechnology (NY) 13: 378-382.

Kang BS, Cooper DR, Devedjiev Y, Derewenda U, Derewenda ZS (2003) Molecular roots of degenerate specificity in syntenin's PDZ2 domain: Reassessment of the PDZ recognition paradigm. Structure 11: 845-853.

Kiczak L, Kasztura M, Koscielska-Kasprzak K, Dadlez M, Otlewski J (2001) Selection of potent chymotrypsin and elastase inhibitors from M13 phage library of basic pancreatic trypsin inhibitor (BPTI). Biochim Biophys Acta 1550: 153-163.

Kimple ME, Siderovski DP, Sondek J (2001) Functional relevance of the disulfide-linked complex of the N-terminal PDZ domain of InaD with NorpA. EMBO J 20: $4414-4422$
Kourlas PI, Strout MP, Becknell B, Veronese ML, Croce CM, Theil KS, Krahe R, Ruutu T, Knuutila S, Bloomfield CD, Caligiuri MA (2000) Identification of a gene at $11 \mathrm{q} 23$ encoding a guanine nucleotide exchange factor: Evidence for its fusion with MLL in acute myeloid leukemia. Proc Natl Acad Sci USA 97: 2145-2150.

Laura RP, Witt AS, Held HA, Gerstner R, Deshayes K, Koehler MF, Kosik KS, Sidhu SS, Lasky LA (2002) The Erbin PDZ domain binds with high affinity and specificity to the carboxyl termini of $\delta$-catenin and ARVCF. $J$ Biol Chem 277: 12906-12914.

Longhurst DM, Watanabe M, Rothstein JD, Jackson M (2006) Interaction of PDZRhoGEF with microtubule-associated protein 1 light chains: Link between microtubules, actin cytoskeleton, and neuronal polarity. I Biol Chem 281: 12030-12040.

Lucast LJ, Batey RT, Doudna JA (2001) Large-scale purification of a stable form of recombinant tobacco etch virus protease. Biotechniques 30: 544-546, 548, 550 passim.

Maximov A, Sudhof TC, Bezprozvanny I (1999) Association of neuronal calcium channels with modular adaptor proteins. J Biol Chem 274: 24453-24456.

Nallamsetty S, Waugh DS (2007) A generic protocol for the expression and purification of recombinant proteins in Escherichia coli using a combinatorial His6-maltose binding protein fusion tag. Nat Protoc 2: 383-391.

Nguyen JT, Turck CW, Cohen FE, Zuckermann RN, Lim WA (1998) Exploiting the basis of proline recognition by $\mathrm{SH} 3$ and WW domains: design of N-substituted inhibitors. Science 282: 2088-2092.

Okuhira K, Fitzgerald ML, Sarracino DA, Manning JJ, Bell SA, Goss JL, Freeman MW (2005) Purification of ATPbinding cassette transporter A1 and associated binding proteins reveals the importance of $\beta 1$-syntrophin in cholesterol efflux. J Biol Chem 280: 39653-39664.

Paduch M, Biernat M, Stefanowicz P, Derewenda ZS, Szewczuk Z, Otlewski J (2007) Bivalent peptides as models for multimeric targets of PDZ domains. Chembiochem 8: 443-452.

Penkert RR, DiVittorio HM, Prehoda KE (2004) Internal recognition through PDZ domain plasticity in the Par6-Pals1 complex. Nat Struct Mol Biol 11: 1122-1127.

Ponting CP (1997) Evidence for PDZ domains in bacteria, yeast, and plants. Protein Sci 6: 464-468.

Rossman KL, Sondek J (2005) Larger than Dbl: New structural insights into RhoA activation. Trends Biochem Sci 30: 163-165.

Runyon ST, Zhang Y, Appleton BA, Sazinsky SL, Wu P, Pan B, Wiesmann C, Skelton NJ, Sidhu SS (2007) Structural and functional analysis of the PDZ domains of human HtrA1 and HtrA3. Protein Sci 16: 2454-2471.

Schepens J, Cuppen E, Wieringa B, Hendriks W (1997) The neuronal nitric oxide synthase PDZ motif binds to $-\mathrm{G}(\mathrm{D}, \mathrm{E}) \mathrm{XV}^{*}$ carboxyterminal sequences. FEBS Lett 409: 53-56.

Smith GP, Scott JK (1993) Libraries of peptides and proteins displayed on filamentous phage. Methods Enzymol 217: 228-257.

Songyang Z, Fanning AS, Fu C, Xu J, Marfatia SM, Chishti AH, Crompton A, Chan AC, Anderson JM, Cantley LC (1997) Recognition of unique carboxyl-terminal motifs by distinct PDZ domains. Science 275: 73-77.

Stricker NL, Christopherson KS, Yi BA, Schatz PJ, Raab RW, Dawes G, Bassett DE, Jr, Bredt DS, Li M (1997) PDZ domain of neuronal nitric oxide synthase recognizes novel c-terminal peptide sequences. Nat Biotechnol 15: 336-342. 
Swiercz JM, Kuner R, Behrens J, Offermanns S (2002) Plexin-B1 directly interacts with PDZ-RhoGEF/LARG to regulate RhoA and growth cone morphology. Neuron 35: $51-63$.

Taya S, Inagaki N, Sengiku H, Makino H, Iwamatsu A, Urakawa I, Nagao K, Kataoka S, Kaibuchi K (2001) Direct interaction of insulin-like growth factor-1 receptor with leukemia-associated RhoGEF. J Cell Biol 155: 809-820.

Togashi H, Nagata K, Takagishi M, Saitoh N, Inagaki M (2000) Functions of a Rho-specific guanine nucleotide exchange factor in neurite retraction. Possible role of a proline-rich motif of KIAA0380 in localization. J Biol Chem 275: 29570-29578.

Tonikian R, Zhang Y, Boone C, Sidhu SS (2007) Identifying specificity profiles for peptide recognition modules from phage-displayed peptide libraries. Nat Protoc 2: 1368-1386.

Vaccaro P, Brannetti B, Montecchi-Palazzi L, Philipp S, Helmer Citterich M, Cesareni G, Dente L (2001) Distinct binding specificity of the multiple PDZ domains of INADL, a human protein with homology to INAD from Drosophila melanogaster. J Biol Chem 276: 4212242130 . van den Berk LC, Landi E, Harmsen E, Dente L, Hendriks WJ (2005) Redox-regulated affinity of the third PDZ domain in the phosphotyrosine phosphatase PTP-BL for cysteine-containing target peptides. FEBS I 272: 3306-3316.

Wong HC, Bourdelas A, Krauss A, Lee HJ, Shao Y, Wu D, Mlodzik M, Shi DL, Zheng J (2003) Direct binding of the PDZ domain of Dishevelled to a conserved internal sequence in the C-terminal region of Frizzled. Mol Cell 12: $1251-1260$.

Yamada T, Ohoka Y, Kogo M, Inagaki S (2005) Physical and functional interactions of the lysophosphatidic acid receptors with PDZ domain-containing Rho guanine nucleotide exchange factors (RhoGEFs). J Biol Chem 280: 19358-19363.

Zhang Y, Yeh S, Appleton BA, Held HA, Kausalya PJ, Phua DC, Wong WL, Lasky LA, Wiesmann C, Hunziker W, Sidhu SS (2006) Convergent and divergent ligand specificity amongst the PDZ domains of the LAP and ZO families. J Biol Chem 281: 22299-22311.

Zhang Y, Appleton BA, Wu P, Wiesmann C, Sidhu SS (2007) Structural and functional analysis of the ligand specificity of the HtrA2/Omi PDZ domain. Protein Sci 16: $1738-1750$. 